\title{
Intervention by Post for Reducing the Chronic Use of High Doses of Proton Pump Inhibitors
}

\author{
Elena Valverde Bilbao $^{1 *}$, Amaia Mendizabal Olaizola1, Guillermo \\ Delgado Alvarado ${ }^{2}$, Itxaso Idoiaga Hoyos ${ }^{3}$ and Daniel Hernández \\ Amunarriz $^{4}$ \\ ${ }^{1}$ Primary Care Pharmacist, Bidasoa Hospital, Hondarribia, Bidasoa Integrated Health- \\ care Organisation (IHO), Osakidetza, Spain \\ ${ }^{2}$ Doctor Specialised in Family and Community Medicine, Irún-Centro Health Centre, \\ Irún, Bidasoa IHO, Osakidetza, Spain \\ ${ }^{3}$ Doctor Specialised in Family and Community Medicine, Dumboa Health Centre, Irún, \\ Bidasoa IHO, Osakidetza, Spain \\ ${ }^{4}$ Gastroenterologist, Bidasoa Hospital, Hondarribia, Bidasoa IHO, Osakidetza, Spain \\ *Corresponding Author: Elena Valverde Bilbao, Primary Care Pharmacist, \\ Bidasoa Hospital, Hondarribia, Bidasoa Integrated Healthcare Organisation (IHO), \\ Osakidetza, Spain.
}

DOI: $10.31080 /$ ASNH.2020.04.0727
Received: June 24, 2020

Published: July 11, 2020

(C) All rights are reserved by Elena Valverde Bilbao., et al.

\begin{abstract}
Objectives: Proton pump inhibitors (PPIs) are among the drugs most commonly prescribed in our setting. The objective of the intervention was to assess whether a letter sent by post is more effective in achieving a reduction/cessation of long-term high-doses of PPI use than usual practice.

Methods: This was a randomised intervention study, with before-and-after outcome measures and a control group, in patients who had an active prescription for PPIs at high doses for at least 6 months. The intervention consisted of sending patients an informative letter by post, in which their doctor invited them to seek an appointment for a medication review. Control group patients did not receive such a letter, and they were treated as usual. The main outcome variable was the number of active prescriptions of each PPI dose (high dose/standard dose/treatment cessation) at 6 months after the intervention.

Results: Six months after the intervention, $8 \%$ of control group patients and $16.4 \%$ of intervention group patients were not on any PPIs. Additionally, among those with active prescriptions for PPIs, $6 \%$ of controls and $20 \%$ of intervention group patients had reduced their intake to the standard dose. Overall, cessation/reduction in the intervention group was higher than in the control group, $36.4 \%$ vs $14 \%$, the difference being significant (22.4\%; $95 \%$ CI: 14.1 to 30.7 ).

Conclusion: Sending a letter by post to patients who had been on high-dose PPI therapy for at least 6 months was found to be more effective for treatment cessation and/or dose reduction than usual practice.

Keywords: Proton Pump Inhibitors; Drugs; Spain
\end{abstract}

\section{Abbreviations}

PPI: Proton Pump Inhibitors; GP: General Practitioner; IHO: Integrated Healthcare Organisation

\section{Introduction}

Proton pump inhibitors (PPIs) are among the drugs most prescribed to and used by patients in our setting, omeprazole being the most widely prescribed drug in the Basque Country (Northern Spain). It is estimated that 1 person in 10 takes PPIs daily, a rate that is lower than in Spain as a whole, but higher than in other European Countries [1,2].

In general, PPIs are considered safe, although they are not riskfree: their long-term use has been associated with osteoporosis- 
related fractures, gastrointestinal infections, pneumonia, hypomagnesaemia, and iron and B12 deficiencies, among other health problems. For this reason, their long-term use is only recommended under certain specific clinical circumstances [1].

Factors that have been implicated in the overuse of these drugs include high rates of long-term use of non-steroidal anti-inflammatory drugs, population ageing, and modern lifestyles, as well as their use for imprecise indications and for minor gastric symptoms [3]. Several strategies have been implemented seeking to reduce this overuse, such as delaying the initiation of PPI treatment, dose reduction, abrupt withdrawal, and substitution with other antiulcer agents, as well as patient education and medication self-management $[4,5]$. In line with this, several years ago, the Department of Health of the Government of the Basque Country and the Basque Health System (Osakidetza) added indicators of PPI use to their list of pharmaceutical prescription indicators [6]. Additionally, in recent years various international guidelines have been published on the deprescription of PPIs [7-9].

In our Integrated Healthcare Organisation (IHO), an intervention seeking to optimise the use of PPIs was launched in 2016 including: a) drafting of a consensus document between primary care doctors, gastroenterologists and primary care pharmacists of the organisation; b) running sessions in primary health centres and the hospital to raise awareness of the situation regarding the prescribing of PPIs in the organisation and recommendations on their optimal use; c) providing information to the community pharmacists in the area of influence and requesting their collaboration to promote the proper use of these drugs, d) sending primary care doctors a list of their patients whose treatment should be reviewed (using local patient identifiers, that is, patient codes assigned by the organisation), e) supplying copies of issues 25 and 27 of i-botika (a magazine containing information for patients) that focused on PPIs to all health centres $[10,11]$ and community pharmacists; and f) disseminating a consensus document on the use of PPIs drafted by the Department of Health of the Government of the Basque Country and Osakidetza, published in May 2016 [1].

This intervention had a positive impact [12], but it was considered that there continued to be a large margin for improvement regarding the proper prescribing of these drugs. In response, we decided to design an intervention focused on patients on long-term high-dose PPI therapy, inviting them to seek an appointment with their general practitioner (GP) to review their medication.

In 1977, the World Health Organization advocated for patient participation in various ways in their own healthcare [13]. Shared decision making is ethically preferable and there is a growing body of evidence of its benefits for patients, doctors and health systems as a whole [14].

In the current study, we sought to involve patients in their own treatment, in this way, offering an opportunity for increasing patient independence and empowerment concerning decision making about their treatment. Given all this, we set out to evaluate the effectiveness of sending letters by post in achieving PPI dose reduction or cessation compared to usual practice.

\section{Methods}

This was a randomised intervention study, with before-andafter outcome measures and a control group, carried out in the Bidasoa IHO, part of the Basque Health Service (Osakidetza) with a catchment population of around 86,000 .

\section{Study population}

Study participants were patients under the care of the IHO who in May 2017 had an active long-term prescription for PPIs at a high dose for at least 6 months. For this, we considered the following to be high doses: more than $20 \mathrm{mg}$ /day of omeprazole, esomeprazole, or rabeprazole; more than $40 \mathrm{mg} /$ day of pantoprazole; and more than $30 \mathrm{mg} /$ day of lansoprazole.

We invited the GPs of the IHO to participate in the study. The patients whose GPs agreed to participate were randomly assigned to the intervention or control group. Patients whose GPs declined to participate were not considered in the analysis, in order to avoid bias that could have been introduced by their inclusion.

\section{Intervention}

The intervention consisted of sending patients a letter by post, in Basque and Spanish, on the adverse effects of unjustified long term use of PPIs, inviting them to seek an appointment with their GP to review their medication. We enclosed with the letter two information sheets $[10,11]$ drafted by the Department of Health of 
the Government of the Basque Country and Osakidetza, which had also been used during the preceding intervention (mentioned in the Introduction section) [12].

Patients in the control group were not sent the letter; rather they received treatment as usual, as did patients of GPs who did not participate. Further, all GPs (intervention group, control group and non-participating GPs) were sent a list of the identifiers of patients on high doses of PPIs, from the pharmacy service, a routine practice that serves as a reminder of who continues receiving this risky prescription and hence should have their medication reviewed.

The study was approved by the Clinical Research Ethics Committee of the Gipuzkoa Healthcare Area (ref. EVB-IBP-2017-01).

\section{Calculation of the sample size and randomisation}

The sample size calculation was based on the hypothesis that there would be a $10 \%$ larger decrease in PPI use (dose reduction or treatment cessation) in the intervention group than in the control group. We estimated that with a minimum of $n=100$ individuals per group, the chi-square test would have a power of $80 \%$ to detect this difference with a level of significance of 0.05 (two-tailed). The calculation was performed with nQuery Advisor 7.0.

Randomisation was carried out using random numbers, generated by $\mathrm{R}$ version 3.1.0, in blocks of two patients. In this way, there would be a difference of no more than 1 in the number of patients allocated to the two groups.

\section{Main outcome variables}

The main outcome variable was the number of active prescriptions as a function of PPI dose (high/standard/cessation) at 6 months after the intervention. Decrease in PPI use (dose reduction or cessation) were also studied as categorical variables (Yes/No). Data were retrieved anonymously from the Osakidetza Business Intelligence application.

\section{Statistical analysis}

Categorical variables are described with frequencies and percentages (\%) and continuous variables with means and standard deviations (SDs). The comparisons between the two groups were carried out using Student's t test for continuous variables and the chi-square test for categorical variables. Finally, the change in the use of PPIs is presented in terms of percentage difference, with the corresponding 95\% confidence intervals. Data analysis was performed using IBM SPSS version 23 and SAS 9.3.
Patient and public involvement

We did not involve patients or the public in our work. Patients undergoing long-term PPI treatment were encouraged to visit their primary care physician to make a decision on their continuation or withdrawal together.

\section{Results}

At the start of the intervention, a total of 693 patients from the Bidasoa IHO met the inclusion criteria. The GPs of 292 of these patients decided not to participate in the study, and therefore, only the remaining 401 patients were randomised to the intervention (n $=201)$ or control $(n=200)$ groups (Figure 1$)$. Three of the patients in the intervention group requested that their data were not included in the study and 3 letters were undelivered due to incorrect addresses, and hence, the intervention group was finally composed of 195 patients.

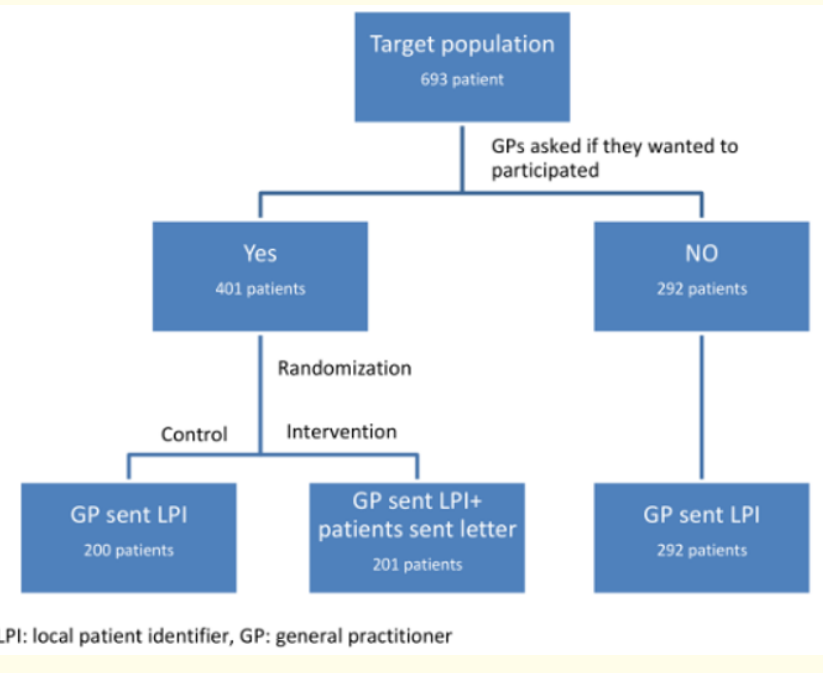

Figure 1: Flowchart of patient randomisation.

The baseline characteristics of the two groups did not differ significantly in age, sex, primary care unit or PPI prescribed (Table 1).

Six months after the intervention, $8 \%$ of patients in the control group and $16.4 \%$ of those in the intervention group did not take any PPIs. Further, $6 \%$ of controls and $20 \%$ of patients in the intervention group had reduced their intake of PPIs to the standard dose. Considering the changes overall, we observed a higher rate of change in the intervention than in the control group, $36.4 \%$ vs $14 \%$, the difference being significant (22.4\%; $95 \%$ CI 14.1 to 30.7 ) (Table 2). 


\begin{tabular}{|l|c|c|c|}
\hline \multicolumn{1}{|c|}{ Variable } & $\begin{array}{c}\text { Control } \\
(\mathbf{n = 2 0 0 )}\end{array}$ & $\begin{array}{c}\text { Intervention } \\
(\mathbf{n = 1 9 5 )}\end{array}$ & p-value \\
\hline Age, years; & $69(14.8)$ & $69(13.6)$ & 0.782 \\
\hline mean (SD) & $28-94$ & $27-94$ & \\
\hline min-max & & & \\
\hline Age categorised, years & $70(35)$ & $66(34)$ & 0.809 \\
\hline$<65$ & $130(65)$ & $129(66)$ & \\
\hline$\geq 65$ & & & \\
\hline Sex; n (\%) & $116(58)$ & $112(57)$ & 0.909 \\
\hline Female & $84(42)$ & $83(43)$ & \\
\hline Male & & & \\
\hline Primary care unit; $\mathbf{n}$ (\%) & $73(37)$ & $64(33)$ & 0.442 \\
\hline Dumboa & $127(64)$ & $131(67)$ & \\
\hline Irún-Centro & & & \\
\hline Active ingredient; $\mathbf{n}$ (\%) & $37(18.5)$ & $39(20)$ & 0.794 \\
\hline Esomeprazole & $3(1.5)$ & $4(2)$ & \\
\hline Lansoprazole & $152(76)$ & $144(74)$ & \\
\hline Omeprazole & $5(2.5)$ & $7(3.5)$ & \\
\hline Pantoprazole & $3(1.5)$ & $1(0.5)$ & \\
\hline Rabeprazole & & & \\
\hline $\begin{array}{l}\text { SD: Standard Deviation; } n \\
\text { (\%): Frequency (Percent- } \\
\text { age); p-value: Based on } \\
\text { Student's t test for continu- } \\
\text { ous variables and the chi- } \\
\text { square test for categorical } \\
\text { variables. }\end{array}$ & & & \\
\hline & & & \\
\hline & & & \\
\hline
\end{tabular}

Table 1: Baseline characteristics of the control and intervention groups.

\begin{tabular}{|c|c|c|c|}
\hline $\begin{array}{c}\text { Changes in PPI dose/day } \\
\text { at } \mathbf{6} \text { months after the } \\
\text { intervention; n (\%) }\end{array}$ & $\begin{array}{c}\text { Control } \\
(\mathbf{n}=\mathbf{2 0 0})\end{array}$ & $\begin{array}{c}\text { Intervention } \\
\text { (n= 195) }\end{array}$ & p-value \\
\hline No change (still on high dose) & $172(86.0)$ & $124(63.6)$ & $<0.0001$ \\
\hline Reduced to standard dose & $12(6.0)$ & $39(20.0)$ & \\
\hline $\begin{array}{c}\text { Cessation of treatment } \\
\text { n (\%): Frequency (Percent- } \\
\text { age); p-value: Based on the } \\
\text { chi-square test for categorical } \\
\text { variables }\end{array}$ & $16(8.0)$ & $32(16.4)$ & \\
\hline
\end{tabular}

Table 2: Changes in the use of proton pump inhibitors (PPIs) at 6 months after the intervention.

On the other hand, the changes observed in the 292 patients whose GPs did not participate in the study (data not shown) were similar to those observed in the control group, 11\% having stopped taking PPIs completely and 5\% having reduced their intake to standard dose.

\section{Discussion}

Patient empowerment is viewed as a philosophy that has implications for individuals, providers, communities and health systems. It is defined as process for identifying needs, taking action and gaining mastery over issues that are self-identified as important. Individual patient participation includes both the right and responsibility to influence treatment and engage in shared decisionmaking. Initial self-management education and on-going support are essential steps for informed participation and in the process of empowerment. The purpose of current empowerment-based care and education is to enhance autonomy and enable the patient to make informed decisions, solve problems and achieve self-determined behavioural goals [15].

The available evidence indicates that sending a letter by post to patients is effective in reducing benzodiazepine intake [16-18]. Regarding PPIs, we only found one study in which patients with dyspepsia received by post a leaflet containing recommendations on the management of dyspepsia and the importance of reducing inappropriate use of PPIs [19]. The main outcome variable was the number of patients who ceased the treatment or reduced their PPI dose and although there was a significant reduction in PPI use at 12 weeks after the intervention, the difference did not remain significant at 20 weeks.

In our study, we found that the strategy of informing patients about their ongoing treatments and involving them in the decision to seek an appointment with their GP to review their medication was more effective in terms of achieving PPI dose reduction or treatment cessation than the usual practice of sending a list of the identifiers of patients with long-term prescriptions for high doses of this medication to the corresponding GPs, such a strategy only involving clinicians.

International studies have demonstrated that a significant number of patients do not have a documented reason for being on PPIs. Concerns about the overuse of these drugs have grown in recent years, but deprescribing studies and guidelines published focus on the way in which deprescribing is carried out (e.g. gradual reduction, abrupt withdrawal, use on demand, or rotation of therapies that do not include a PPI) $[8,20]$. On the other hand, it has been found that patients are generally receptive to medication changes if they are sure that, if necessary, they could be put back on their previous medication [4].

The novelty of our study lies in the fact that it is focused on patients, seeking to motivate them to discuss the possibility of with- 
drawing or reducing the dose of the medication with their own doctor. Our results are in agreement with previous studies [1618] in which $24-65 \%$ of patients taking benzodiazepines who received a similar informative letter had reduced their dose or completely ceased using these drugs at 6 months after the intervention. In these studies and in ours, the intervention was more effective than the control strategy. In contrast, in the only previous study in which a letter was sent to patients on PPIs [19], though a significant reduction was observed at 12 weeks after the intervention, the difference was not maintained to 20 weeks.

The limitations of our study include the fact that the clinicians participated on a voluntary basis. Another potential limitation is the bias that could have affected the control group; given that GPs had patients in both intervention and control groups, it could be the case that their professional interest may have had an impact on the management of controls. Nevertheless, in the light of the results obtained in the group of patients who did not participate in the study, the risk of this bias can be considered to be relatively low. On the other hand, the study was based on considering the medications for which patients had active prescriptions in their medical record; we did not check whether the medication was collected from the pharmacy or assess consultations that may have arisen due to the receiving the letter. In future research, therefore, it would be interesting to investigate treatment adherence of these patients and determine the number of consultations generated by the intervention.

\section{Conclusion}

Sending a letter by post to patients who have been on long-term high-dose PPI therapy for at least 6 months seems to be more effective in achieving dose reduction and/or cessation of these drugs than sending a list of the identifiers of such patients, who should have medication reviews, to their GPs. From this, we can conclude that empowering patients through the provision of information and involving them in decision making may be a more effective approach than the current practice which only involves providing information to GPs.

\section{Clinical Research Ethics Committee Approval}

The study was approved by the Clinical Research Ethics Committee of the Gipuzkoa Healthcare Area (ref. EVB-IBP-2017-01).

\section{Consent for Publication}

Not applicable.

\section{Availability of Data and Materials}

The datasets used and/or analysed during the current study are available from the corresponding author on reasonable request.

\section{Conflicts of Interest}

None declared.

\section{Funding}

No external funding was received for conducting this study.

\section{Authors' Contributions}

Elena Valverde and Amaia Mendizabal contributed to the design of the study, the preparation and presentation of documents necessary for obtaining ethics committee approval for the study, and the drafting of the manuscript.

Guillermo Delgado and Itxaso Idoiaga contributed to the design of the study and participated actively in the study as GPs of both intervention and control group patients, as well as to edition of the manuscript.

Daniel Hernández contributed to the design of the study and edition of the manuscript.

\section{Acknowledgements}

The authors would like to thank all the clinicians of the Bidasoa IHO who participated in the study. We are also grateful to the Gipuzkoa Primary care-IHO Research Unit for their invaluable help with preparing the protocol for the study, patient randomisation and data analysis, as well as the drafting of this manuscript.

\section{Bibliography}

1. "Inhibidores de la Bomba de protones: Recomendaciones de Uso". Departamento de Salud (2016).

2. Utilización de medicamentos antiulcerosos en España durante el periodo 2000-2012. Informe de utilización de medicamentos U/AUL/V1/15012014. Agencia Española de Medicamentos y Productos Sanitarios.

3. García del Pozo J. "Estudio de utilización de antiulcerosos en España (2000-2008)”. Información terapeútica del Sistema Nacional de Salud 33 (2009): 49-54.

4. Pollock K and Grime J. "Strategies for reducing the prescribing of proton pump inhibitors (PPIs): patient self-regulation of treatment may be an under-exploited resource". Social Science and Medicine 51 (2000): 1827-1839. 
5. Haastrup P., et al. "Strategies for discontinuation of proton pump inhibitors: a systematic review". Family Practice 31.6 (2014): 625-630.

6. Department of Health, Basque Government. Manual de evaluación. Anexo II Contrato Programa 2018. OSIs. Versión 11 de abril de 2018. Dirección de Aseguramiento y Contratación Sanitaria (2018).

7. Tenni P and Dunbabin D. “A guide to deprescribing for better health outcomes: Proton pump inhibitors" (2016).

8. Farrel B., et al. "Deprescribing proton pump inhibitors. Evidence-based clinical practice guideline". Canadian Family Physician 63 (2017): 354-364.

9. Therapeutics Initiative. "Evidence based drug therapy. Deprescribing proton pump inhibitors". Therapeutics Letter 111 (2018): 1-2.

10. Omeprazoles los justos. i-botika 25 (2016).

11. Omeprazoles, quizá sea el momento de dejarlos. i-botika 27 (2016).

12. Valverde Bilbao E., et al. "Intervención para optimizar el uso adecuado de inhibidores de la bomba de protons". Libro de comunicaciones X Jornada de Seguridad del Paciente en Atención Primaria (2017).

13. Holmström I and Röing M. "The relation between patient-centeredness and patient empowerment: A discussion on concepts". Patient Education and Counseling 79 (2010): 167-172.

14. Ciapponi A. "Toma de decisions compartidas" 15.1 (2012): 2-4.

15. Funnell MM. "Patient empowerment: What does it really mean?" Patient Education and Counselling 99 (2016): 19211922.

16. Cormack MA., et al. "Evaluation of an easy, cost-effective strategy for cutting benzodiazepine use in general practice". British Journal of General Practice 44 (1994): 5-8.

17. Heather N., et al. "Randomised controlled trial of two brief interventions against long-term benzodiazepine use: outcome of intervention". Addiction Research and Theory 12.2 (2004): 141-154.
18. Gorgels WJ., et al. "Discontinuation of long-term benzodiazepine use by sending a letter to users in family practice: a prospective controlled intervention study". Drug and Alcohol Dependence 78 (2005): 49-56.

19. Krol N., et al. "Patient-directed strategy to reduce prescribing for patients with dyspepsia in general practice: a randomized trial". Alimentary Pharmacology and Therapeutics 19 (2004): 917-922.

20. Kim J., et al. "Strategies for effective discontinuation of proton pump inhibitors". Current Gastroenterology Reports 20.6 (2018): 27.

\section{Assets from publication with us}

- Prompt Acknowledgement after receiving the article

- Thorough Double blinded peer review

- Rapid Publication

- Issue of Publication Certificate

- High visibility of your Published work

Website: www.actascientific.com/

Submit Article: www.actascientific.com/submission.php Email us: editor@actascientific.com

Contact us: +919182824667 